\title{
Argumentação na sala de aula e seu potencial metacognitivo como caminho para um enfoque CTS no ensino de química: uma proposta analítica
}

Sylvia De Chiaro'

Kátia Aparecida da Silva Aquino"

\section{Resumo}

0 ensino de química muitas vezes é guiado pela utilização de fórmulas e esquemas, dada a natureza dos símbolos que permeiam tal disciplina. Nesse cenário, são poucos os estudos que tratam de aspectos ligados ao processo de reflexão usando temas na área de ciências exatas. Assim, fazer parte da formação de indivíduos críticos e reflexivos em relação ao conhecimento, a eles mesmos e ao ambiente social e natural em que vivem tem sido preocupação de educadores e psicólogos e está na base do movimento CTS Ciência, Tecnologia e Sociedade. Este estudo, apoiando-se no potencial metacognitivo da argumentação na educação, amplia essa discussão ao investigar se a utilização desse tipo de discurso propicia aos alunos a reflexão sobre seus próprios pensamentos, mostrando um funcionamento ao nível metacognitivo necessário ao enfoque CTS em sala de aula. Foram analisadas produções textuais de três alunos em aulas de química no ensino médio, nas quais se solicitava o posicionamento destes diante da pergunta "Radioatividade: vida ou morte?", após serem realizados debates sobre esse tema. As análises mostraram que a argumentação, por sua organização discursiva peculiar, se constitui em interessante alternativa para fazer emergir formas de pensamento sofisticadas, como as que definem um pensamento crítico e reflexivo.

\section{Palavras-chave}

Argumentação - Metacognição - CTS: Ciência, Tecnologia e Sociedade - Ensino de química.

I- Universidade Federal de Pernambuco, Recife, PE, Brasil.

Contato: chiaro@hotlink.com.br

II- Universidade Federal de Pernambuco,

Recife, PE, Brasil.

Contato: aquino@ufpe.br 


\title{
Argumentation in classroom and its metacognitive potential as a way to an STS approach to teaching chemistry: an analytical proposal
}

Sylvia De Chiaro'

Kátia Aparecida da Silva Aquino"

\begin{abstract}
The teaching of chemistry is often guided by the use of formulae and schemes, given the nature of the symbols pervading this discipline. In this scenario, few studies deal with aspects associated with the process of reflection involving themes of exact sciences. Thus, being part of the education of critical, reflective individuals with regard to knowledge, to themselves and the social and natural environment they live in has been a concern of educators and psychologists and is in the basis of the STS (Science, Technology and Society) movement. Building on the metacognitive potential of argumentation in education, this study widens this discussion by investigating whether the use of this type of discourse allows students to reflect about their own thoughts, showing a functioning at the metacognitive level that is necessary to an STS approach in classroom. We analyzed the texts written by three students in chemistry classes in secondary education during which they were required to express their opinion on the question "Radiation: life or death?", after debates had been conducted about this subject. Our analyses showed that argumentation, due to its peculiar discursive organization, is an interesting alternative to promote the emergence of sophisticated forms of thought, such as the ones that define critical and reflective thinking.
\end{abstract}

\section{Keywords}

Argumentation - Metacognition - Science, technology and society (STS) - Chemistry teaching.

I- Universidade Federal de Pernambuco, Recife, PE, Brasil.

Contact: chiaro@hotlink.com.br

II- Universidade Federal de Pernambuco, Recife, PE, Brasil.

Contact: aquino@ufpe.br 


\section{Introdução}

Pesquisadores e educadores dos mais diversos domínios da ciência educacional têm demonstrado crescente interesse em estudar maneiras de promover a construção do conhecimento e o desenvolvimento das habilidades de raciocínio de seus alunos. Estudos relacionados à utilização da argumentação em sala de aula (CANDELA, 1998; BAKER, 2009; SCHWARZ, 2009; LEITÃO, 2007, 2009; 2011; JIMENEZ-ALEIXANDRE; ERDURAN, 2008; DE CHIARO, 2001; DE CHIARO; LEITÃO, 2005) vêm mostrando o enorme potencial desse tipo de discurso para os fins acima explicitados. Isso porque a sua própria organização discursiva possibilita aos indivíduos envolvidos reflexões num nível não apenas cognitivo, mas também metacognitivo, já que leva os envolvidos a movimentos de revisão e de construção de conhecimentos a partir da reflexão sobre seus próprios pensamentos. A argumentação no ensino das ciências também tem sido amplamente estudada nos últimos anos a partir de diferentes perspectivas (JIMENEZALEIXANDRE, 2006; NASCIMENTO; VIEIRA, 2008; MENDONÇA; JUSTI, 2013; MENDES; SANTOS, 2013; SASSERON; CARVALHO, 2013; JIMENEZ-ALEIXANDRE; BROCOS, 2015), como por exemplo abordagens: (1) mais focadas em compreender a estrutura dos argumentos construídos; (2) direcionadas ao desenvolvimento de habilidades argumentativas; (3) interessadas em entender o papel da argumentação na construção de um ambiente de reflexividade em sala de aula, entre outras. Tendo como base pesquisas recentes (DE CHIARO, 2006; DE CHIARO; AQUINO, 2013) a respeito do desenvolvimento metacognitivo de alunos envolvidos em situações de argumentação, o presente estudo se insere no esforço de ampliação dessas reflexões no domínio das ciências, buscando contribuir para essa terceira linha de estudos citada, ao propor uma ferramenta analítica que ajude a compreender melhor o potencial metacognitivo da argumentação como caminho para um enfoque CTS - Ciência, Tecnologia e Sociedade no ensino de química.

A área das ciências e também a da tecnologia têm sido responsáveis nas últimas décadas por grandes transformações na ciência de forma geral e, consequentemente, na sociedade. Para além do pensamento simplista de que essas transformações só podem trazer o bem para o homem e o desenvolvimento para a sociedade, é de suma importância que o aluno reflita criticamente sobre os interesses que estão na base dessas transformações, desde os de caráter social, político, econômico e até os militares, bem como suas consequências. Essas reflexões acontecem no âmbito do que chamamos de discussões sociocientíficas, que vêm mostrando a relevância da utilização de um enfoque CTS no ensino.

Mais especificamente direcionado ao ensino de química, estudos recentes vêm apontando interessantes reflexões sobre a relação entre questões sociocientíficas nesse domínio de conhecimento e a argumentação. Fatareli, Ferreira e Queiroz (2014), por exemplo, mostram que a análise pelos alunos de textos de divulgação científica (TDC) - no referido estudo, um texto relacionado à questão do urânio empobrecido - se constitui em uma interessante estratégia didática, que pode promover não apenas a apropriação do conteúdo e forma textual, mas ainda, a identificação dos elementos controversos e contraditórios presentes propiciando, a partir de debates, o desenvolvimento do espírito crítico e reflexivo, fundamentais a uma abordagem CTS. Seguindo o mesmo raciocínio, Fatareli; Massi; Ferreira e Queiroz (2015) discutem elementos para o mapeamento de TDCs potencialmente desencadeadores de debate, defendendo a importância de um bom planejamento em relação aos materiais de apoio utilizados pelo professor de forma que esses possam se constituir em fontes de motivação da argumentação e reflexão em sala de aula de química.

Quando se ressalta, pois, a importância dos questionamentos críticos e reflexivos a respeito do contexto científico, tecnológico 
e social, encontramos um lugar especial para a argumentação em sala de aula. Este foi o ponto crucial deste estudo: colaborar com a investigação sobre a utilização da argumentação no contexto de sala de aula como uma alternativa possível no que diz respeito à emergência e à manutenção de um funcionamento metacognitivo, necessário ao exercício da reflexividade e criticidade desejada na construção dos conhecimentos científicos dos alunos em aulas de química. Nesse sentido, quanto ao conteúdo "Radioatividade", alunos do terceiro ano do ensino médio foram convidados a debater e posteriormente escrever sobre a questão “Radioatividade, vida ou morte?", em quatro momentos no decorrer de um mês de aulas sobre a temática em questão. Os relatos escritos dos alunos, posteriores às situações de argumentação geradas pela questão, foram analisados com o objetivo de se perceber indícios de movimentos metacognitivos dos alunos na construção de conhecimentos sobre a questão sociocientífica levantada.

\section{O enfoque CTS, as discussões sociocientíficas e a argumentação}

0 movimento CTS tem crescido enormemente na área educacional nos últimos anos, especialmente após a inserção desse debate nos Parâmetros Curriculares Nacionais (PCN). Nesse documento curricular, ao se estabelecer um ensino voltado para o contexto social, incentivase que as escolas promovam a interação do aluno com questões científicas e tecnológicas em suas dimensões sociais. Dessa forma, espera-se que o aluno consiga, cada vez mais, relacionar o conhecimento científico e tecnológico com as situações do seu dia a dia na sociedade, estabelecendo vínculos com sua própria vida e a de sua comunidade e, consequentemente, construindo maior sentido aos conteúdos estudados. Vários são os estudos que apontam nessa direção (PINHEIRO; SILVEIRA; BAZZO, 2007; MUNDIM; SANTOS, 2012; AULER;
DELIZOICOV, 2006) a fim de ampliar essa discussão, de possibilitar a recuperação ou mesmo a construção de espaços críticos na escola e além de seus muros e de, portanto, possibilitar aos nossos jovens o desenvolvimento de uma postura questionadora e crítica diante do desenvolvimento científico e tecnológico.

Do ponto de vista da prática pedagógica, a proposta desse enfoque implica profundas mudanças em relação a concepções tradicionais de ensino que ainda predominam em muitas escolas, já que se buscam novas formas de entender e construir o saber científico. Há nessa nova postura uma tentativa de superação de uma neutralidade científica irreal a fim de se romper com um ensino de repetição e de estimular a reflexão, o questionamento e o desenvolvimento da criatividade e da imaginação. 0 saber deixa de ser sagrado e impalpável e passa a ser descoberto e pesquisado pelo professor e pelos alunos, juntos. Um ensino baseado nessa proposta busca, além da compreensão de conhecimentos de forma contextualizada e crítica, o desenvolvimento de habilidades e competências para que o aluno possa ser capaz de estabelecer relações intersubjetivas com a construção do conhecimento que o permitam opinar sobre o saber, reagir, reelaborá-lo, ampliá-lo. É nesse sentido que propomos que a inserção de situações de argumentação em sala de aula pode ser interessante.

Estudos recentes já vêm apontando a relação entre argumentação e discussões sociocientíficas, como em Mendes e Santos (2013). Nesse estudo, os autores mostram que os professores pesquisados estabelecem um contexto propício à argumentação ao promoverem discussões sociocientíficas. Sob uma ótica semelhante, o presente estudo busca ampliar essa reflexão, no entanto, partindo do sentido inverso, isto é, procurou-se aqui investigar se a utilização da argumentação como recurso didático no estudo do tema "Radioatividade" propiciaria aos alunos envolvidos a reflexão sobre seus próprios pensamentos, sua ampliação ou reconstrução; ou seja, se essa 
estratégia favorece um funcionamento no nível metacognitivo necessário a um enfoque CTS em sala de aula. Aqui se propõe, portanto, que a argumentação se constitui em interessante recurso quando a intenção da escola é promover um ensino contextualizado, reflexivo e voltado ao desenvolvimento de indivíduos comprometidos com a realidade social.

\section{Argumentação e metacognição}

0 estudo sobre a metacognição tem sido encontrado com focos diversos na literatura acadêmica que discute aprendizagem e desenvolvimento cognitivo. Normalmente, o uso desse termo reflete o envolvimento do pesquisador em uma linha de investigação específica. Originalmente utilizado por Flavell (1979), o termo metacognição é compreendido enquanto processo no qual os indivíduos monitoram e controlam seu próprio funcionamento cognitivo. 0 foco de estudo desse autor é cognitivista e, portanto, está na esfera das operações mentais. No presente estudo, o foco recai no papel da linguagem e da comunicação em geral no desenvolvimento cognitivo, uma vez que aqui se assume uma relação constitutiva entre linguagem e cognição humana, proposta pelas teorias sócio-históricas, em especial Vygotsky (1993).

Em concordância com Mercer (2013) e Whitebread (2013), neste estudo não apenas compreendemos que a metacognição se refere à habilidade do indivíduo de pensar sobre seus próprios pensamentos, como ainda que diferentes formas de uso da linguagem podem ter diferentes influências no desenvolvimento cognitivo e metacognitivo desse indivíduo. É nesse sentido que surge o interesse em entender as relações entre uma forma específica de organização linguística, a argumentação, e o desenvolvimento metacognitivo.

A compreensão da argumentação em sala de aula como uma maneira de ampliar a complexidade do conhecimento, as possibilidades de revisão crítica deste e, assim, a qualidade do raciocínio envolvido pode ser encontrada na literatura de autores como Rapanta, GarciaMila e Gilabert (2013) e Kuhn (1991, 2005). Esses autores defendem que tais possibilidades de pensamento de alta ordem - basicamente definido como controle metacognitivo e propiciado pela argumentação - resultam em ganhos educacionais. Para eles, a argumentação parece propiciar oportunidades aos estudantes de refınarem suas compreensões sobre determinado assunto, possibilitando-os separar aquilo que é relevante do que é irrelevante, fazer conexões entre contextos e ampliar o poder explicativo de seus conhecimentos.

Mais especificamente, no presente estudo, defendemos que é a própria organização discursiva da argumentação que lhe confere um caráter inerentemente metacognitivo (DE CHIARO, 2006; LEITÃO, 2007, 2008). Composta de argumento (ponto de vista + justificativa), contra-argumento e resposta, a argumentação se caracteriza pela construção, justificação, negociação e, ainda, pela possível modificação de pontos de vista. A partir desses movimentos, os envolvidos na situação de argumentação são levados a um deslocamento de foco de atenção do assunto em questão para as bases e os limites daquilo que se pensa sobre o tema. Esse deslocamento, em termos de funcionamento psicológico, corresponde ao deslocamento de um funcionamento cognitivo para um funcionamento metacognitivo. Defende-se ainda que esse deslocamento do pensamento a um metapensamento pode acontecer a partir de três diferentes movimentos metacognitivos: mantenedor, elaborador ou reconstrutor do pensamento (DE CHIARO, 2006). Mantenedor, quando o aluno reflete sobre suas próprias posições, e decide mantê-las como estão; elaborador, quando o movimento de pensar sobre seus próprios pensamentos leva ao estabelecimento de novas relações e conexões com a posição inicial, ampliando-a, e reconstrutor, na medida em que essa autorreflexão se caracteriza pela dúvida sobre os próprios posicionamentos e busca de novas possibilidades. 
$\mathrm{Na}$ interseção das duas temáticas em foco, argumentação e metacognição, propõese, portanto, que, diante de um pedido de justificativas de um posicionamento ou na eminência de uma resposta a um contraargumento - movimentos característicos da ocorrência de dilemas e de oposições numa situação de argumentação em sala de aula -, o aluno é levado a um funcionamento metacognitivo que pode se caracterizar: (1) pela manutenção de sua posição inicial; (2) pelo estabelecimento de novas conexões, de novas ideias e de relações com sua posição inicial, ao elaborá-la; ou ainda (3) pelo redirecionamento para novas alternativas, ao reconstruí-la quando sua posição inicial se torna incerta. A partir de uma prática pedagógica previamente estruturada que envolveu argumentação em sala de aula, essas diferentes possibilidades de pensamento foram investigadas como indícios da ocorrência de um funcionamento ao nível metacognitivo nos alunos investigados.

\section{Procedimentos metodológicos}

Realizada em uma sala de aula de química do terceiro ano do ensino médio do Colégio de Aplicação da Universidade Federal de Pernambuco (CAp/UFPE) ${ }^{1}$, esta pesquisa aconteceu durante a unidade relativa ao tema "Radioatividade". Essa temática foi escolhida não somente levando-se em consideração o calendário da pesquisa, mas especialmente por ser uma questão bastante controversa e considerada pela professora de química como um tema que favorece ricos debates se trabalhado no âmbito de discussões sociocientíficas.

A atividade, planejada antecipadamente, alternava uma produção escrita individual de tema "Radioatividade: vida ou morte?" e debates em grupo sobre essa questão. A primeira resposta a essa pergunta inaugurou

1- Os nomes citados neste trabalho são fictícios e toda a pesquisa foi conduzida com o consentimento informado aprovado pelo Comitê de Ética em Pesquisa da Universidade Federal de Pernambuco Centro de Ciências da Saúde / UFPE-CCS. Parecer: 17358. as aulas sobre a temática, sendo, portanto, realizada antes de qualquer conteúdo sobre esse tema ter sido trabalhado em sala de aula. Ao todo foram quatro escritas intercaladas com três debates. Cada um dos debates aconteceu em um momento diferente do trabalho sobre a temática, tendo o primeiro ocorrido logo após a primeira escrita. Em seguida, realizou-se a primeira discussão em grupo sobre a temática, à qual se seguiu uma nova resposta escrita. 0 segundo debate foi realizado na aula posterior, depois de os alunos serem instruídos a lerem o livro-texto e a buscarem outras fontes sobre o tema "Radioatividade" em casa. Também a esse debate seguiu-se nova resposta escrita. 0 terceiro debate aconteceu depois de um mês de aula e teve uma estrutura prévia combinada com os alunos: a composição de três grupos, sendo um proponente de um projeto envolvendo radioatividade; outro composto por um "júri popular"; e o outro composto pelo "governo". Esses dois últimos tinham a função de avaliar e julgar a pertinência da proposta do primeiro. A última resposta escrita foi realizada após essa atividade. Um resumo desse procedimento metodológico pode ser visto no quadro abaixo:

\section{Quadro 1}

\begin{tabular}{|c|c|c|}
\hline AULA & MOMENTO & ATIVIDADE \\
\hline \multirow{3}{*}{1} & Início & $\begin{array}{l}\text { Primeira resposta escrita à pergunta } \\
\text { "Radioatividade: vida ou morte?" }\end{array}$ \\
\hline & Pós-resposta & $\begin{array}{c}\text { Primeiro debate sobre a questão } \\
\text { respondida }\end{array}$ \\
\hline & Final & $\begin{array}{l}\text { Segunda resposta escrita à pergunta } \\
\text { "Qual sua opinião sobre o tema } \\
\text { 'Radioatividade: vida ou morte' neste } \\
\text { momento e como chegou a ela?" }\end{array}$ \\
\hline Casa & $\begin{array}{l}\text { Da primeira para } \\
\text { segunda aula }\end{array}$ & $\begin{array}{l}\text { Leitura do livro-texto e outras } \\
\text { consultas }\end{array}$ \\
\hline \multirow{2}{*}{2} & Início & $\begin{array}{c}\text { Segundo debate sobre a mesma } \\
\text { questão respondida }\end{array}$ \\
\hline & Pós-debate & $\begin{array}{c}\text { Terceira resposta escrita à mesma } \\
\text { pergunta }\end{array}$ \\
\hline CAp & Um mês/aula & $\begin{array}{l}\text { Aulas teóricas, preparação de } \\
\text { atividade de debate estruturado }\end{array}$ \\
\hline \multirow{2}{*}{3} & Início & Debate estruturado \\
\hline & Pós-debate & $\begin{array}{l}\text { Quarta resposta escrita à mesma } \\
\text { pergunta }\end{array}$ \\
\hline
\end{tabular}

Fonte: protocolo da pesquisa. 
Por meio dessa atividade, tencionouse tanto fazer emergir a argumentação entre os alunos como ter um registro escrito sobre o processo de pensamento dos mesmos no decorrer dos debates e em função deles. Para agregar mais informações no sentido de poder relacionar, de fato, os movimentos de construção dos alunos com as situações de argumentação vivenciadas pelos mesmos, ao responder às três últimas versões da pergunta, isto é, aquelas escritas pós-debate, os alunos também eram convidados a escrever, no verso da folha, como acreditavam ter chegado àquela opinião naquele momento.

Três alunos escolhidos aleatoriamente tiveram seu material analisado. Formas de regulações discursivas apontadas na literatura (CARON, 1983; CHABROL, 1994; CHABROL; OLRY-LOUIS, 2007; CHABROL; RADU, 2008) que são mobilizadas a partir de modalizações e de interrupções no discurso serviram de apoio para esta análise, uma vez que a mesma se realiza em um estudo que assume essa perspectiva de constitutividade entre linguagem e cognição (VYGOTSKY, 1993). Isto é, se a linguagem constitui a cognição, é preciso atentar, então, para os recursos linguísticos que sinalizam como o enunciador comenta o próprio discurso - modalizações - e como aparentemente o controla a partir das diferentes formas com que o interrompe. Este nos parece constituir um caminho promissor para se compreender essa relação entre linguagem e cognição.

As diferentes formas de interrupção discursiva pontuadas na literatura acima foram relacionadas com os movimentos metacognitivos em estudos anteriores (DE CHIARO, 2006; DE CHIARO; AQUINO, 2013), a saber: (1) interrupções do tipo simples - que acontecem a partir de pausas, hesitações e/ ou silêncios que são seguidos da repetição do mesmo conteúdo textual - foram relacionadas com o movimento metacognitivo mantenedor; (2) interrupções com adições, mas sem ruptura, - cuja mudança discursiva envolve um aprofundamento do conteúdo que está sendo construído pela inclusão de novas proposições ao mesmo - mostraram semelhanças com o movimento elaborador; e (3) interrupções com ruptura e autocorreção - que caracterizam mudança no curso discursivo - pareceram implicar um movimento do tipo reconstrutor.

Assim, partindo dos estudos supracitados - e ainda nos apoiando nos operadores argumentativos presentes $(\mathrm{KOCH}, 2000 ; \mathrm{KOCH}$; MORATO; BENTES, 2005) - empreendemos a análise dos textos selecionados. Ao se refletir sobre a possibilidade de desenvolvimento metacognitivo a partir das situações de argumentação pesquisadas, resultados muito interessantes ao objetivo deste estudo foram encontrados nos escritos dos três alunos analisados. Para ilustrar as conclusões a que essas discussões apontam, recortes da análise dos três alunos serão mostrados a seguir.

\section{Análise e discussão}

De forma geral, a análise dos três alunos aponta para um intenso movimento metacognitivo na construção de seus posicionamentos ao longo de toda a atividade. Movimentos dos três tipos - mantenedor, elaborador e reconstrutor - foram encontrados em seus textos escritos analisados, assim como nos depoimentos sobre como estavam chegando aos seus posicionamentos naquele momento. A referência aos debates como importante impulsionador de suas reflexões foi uma constante.

Cientes do prejuízo, em termos da riqueza da análise realizada, em relação à impossibilidade de retratar neste texto todas as três análises dos quatro registros escritos de cada aluno na íntegra, optou-se por selecionar um recorte de cada aluno para se elucidar a presença dos três movimentos na construção discursiva destes. Assim, em cada um dos movimentos que se quer demonstrar, está abaixo identificado não só o aluno (por um nome fictício), mas ainda em que ponto da análise do curso de suas construções foi 
feito o recorte que caracteriza a presença do movimento em foco. Após a identificação do ponto do recorte, segue-se uma transcrição literal dos textos selecionados ${ }^{2}$ e a análise propriamente dita.

\section{Monitoramento mantenedor - Aluna Suzana}

\section{Recorte: análise dos Registros 3 e 4}

Quadro 2 - Reprodução do Registro 3, correspondente à resposta de Suzana para a questão "Radioatividade: vida ou morte? Qual sua opinião sobre o tema neste momento e como chegou a ela?"

"A radioatividade enquanto elemento da natureza pode ser considerada vida. Quando manipulada pelo ser humano pode acarretar graves consequências, se não foram tomados os devidos cuidados".

Como?

"Por meio das discussões em sala de aula e pelo o que eu pesquisei".

Fonte: protocolo da pesquisa.

Quadro 3- Reprodução do Registro 4, correspondente à resposta de Suzana para a questão "Radioatividade: vida ou morte? Qual sua opinião sobre o tema neste momento e como chegou a ela?"

"A radioatividade natural é, sem dúvida, vida, já que convivemos com ela no nosso dia a dia sem nenhum problema. Já a radioatividade manipulada pelo homem pode ser vida, quando usada de modo cuidadoso, ou morte, caso haja um uso indiscriminado dela".

\begin{tabular}{|c|c|}
\hline Como? & $\begin{array}{c}\text { "Através das várias pesquisas feitas, dos debates que } \\
\text { houveram em sala, das aulas dadas sobre o tema e } \\
\text { do trabalho da elaboração de um projeto envolvendo a } \\
\text { radioatividade". }\end{array}$ \\
\hline
\end{tabular}

Fonte: protocolo da pesquisa

A escolha desses dois recortes da aluna Suzana para elucidar a presença de um movimento do tipo mantenedor se deveu não apenas ao fato de encontramos nesses dois registros o mesmo ponto de vista, mas

2- As transcrições dos textos são literais, respeitando a forma como 0 próprio aluno escreveu, independentemente da adequação gramatical. principalmente pelas circunstâncias em que essa manutenção acontece. É que esse ponto de vista se manteve mesmo levando-se em consideração que, entre os registros três e quatro, transcorreu-se, além de um mês de aula e reflexões sobre a temática, a construção de um trabalho sobre radioatividade que exigia não simplesmente uma reprodução dos conteúdos sobre o tema, mas - independentemente do grupo em que os alunos estivessem inseridos - a construção de posicionamentos críticos. 0 desenvolvimento dessa competência, desse modo, propiciou, no dia da apresentação do trabalho, uma discussão sociocientífica entre esses grupos sobre a implantação de um projeto que envolvesse a utilização da radioatividade. A título de curiosidade, a proposta em questão foi a Implantação de Irradiador de Alimentos no Vale do São Francisco Pernambucano, projeto fictício construído pelos alunos que traz subjacente uma questão sociocientífica de extrema importância e atualidade.

0 que se quer dizer com as observações acima é que essas circunstâncias explicitadas nos ajudam a defender que a permanência do mesmo discurso não parece ter acontecido por falta de elementos, por desinteresse ou por descompromisso pelo assunto. Ao contrário, essas circunstâncias nos dão indícios de que essa manutenção reflete um permanecer resultante de uma reflexão sobre outras possibilidades levantadas tanto nas aulas como na construção dos argumentos para o trabalho. Essas outras possibilidades puderam ser constatadas tanto nos debates como na escrita dos demais alunos e nas defesas dos grupos na atividade final descrita. Além disso, as duas respostas da própria aluna ao modo como ela chegou a essa opinião corroboram essa observação, já que, em ambas, ela mesma confirma que seu ponto de vista advém não só das aulas, mas dos debates, das discussões e da elaboração do projeto.

As marcas discursivas também nos ajudam a defender essa constatação. No Registro 3, Suzana traz seu ponto de vista 
ao enunciar que "a radioatividade enquanto elemento da natureza pode ser considerada vida”. Apesar de não utilizar nenhum marcador explícito de tomada de posição do tipo "eu acho que”, é possível, mediante a forma afirmativa que constrói esse enunciado, perceber que o mesmo sustenta uma posição de forma clara. Interessante, no entanto, comentar que sua tomada de posição sobre um dos lados da questão, "vida”, traz uma condição explícita: "enquanto elemento da natureza”. 0 marcador discursivo "enquanto" aparece aqui como um tipo de operador argumentativo descrito por Koch (2000) como um conector circunstancial, posicionado anteposto a um enunciado que explicita uma condição; significa dizer, então: radioatividade é vida desde que considerada como elemento da natureza. 0 outro posicionamento que dá continuidade a este primeiro é construído da mesma forma, considerando-se agora a outra circunstância refletida pela aluna: radioatividade manipulada pelo homem. Nesse caso, o "quando" utilizado pela aluna também denota essa mesma função circunstancial: "quando manipulada pelo ser humano pode acarretar graves consequências”. Aqui, entre um posicionamento e outro, podemos considerar de forma implícita a presença de um operador argumentativo que tem a função de contrapor argumentos orientados para conclusões contrárias, como o "mas"; vejamos: "enquanto elemento da natureza a radioatividade pode ser considerada vida, mas quando manipulada pelo homem pode acarretar graves consequências”. Para concluir seu argumento, Suzana, utilizando novamente um conector que traz a ideia de circunstancialidade/pressuposição, o "se", justifica seu ponto de vista: "se não forem tomados os devidos cuidados".

No Registro 4, a aluna mais uma vez traz essas duas condições de conceber a radioatividade como elemento natural e manipulado pelo homem e, da mesma forma, atrela a cada uma, respectivamente, a ideia de vida e de possível morte. Inclusive a justificativa para essa última aparece da mesma forma: sob a condição da forma como a radioatividade é utilizada (ela usa "sem os devidos cuidados" no terceiro texto e "uso indiscriminado" no quarto). Do ponto de vista do conteúdo, portanto, podemos dizer que seu posicionamento se mantém entre os dois registros, mas, mais do que isso, o que se quer mostrar aqui é que essa manutenção acontece de forma reflexiva, ou seja, a partir de um movimento metacognitivo mantenedor.

Para justificarmos essa constatação, recorremos a alguns elementos discursivos que nos chamam atenção. Com o intuito de retomar seu posicionamento, Suzana desta vez se utiliza de uma marca linguística, o "sem dúvida”, que, segundo Chabrol (1994), reflete a expressão da opinião do enunciador em relação a algo que já foi dito antes; nesse caso, seu próprio posicionamento no Registro 3. Comentar o próprio discurso é uma marca de modalização característica de movimentos autorreflexivos. Outras operações discursivas reflexivas presentes nesse Registro 4 nos dão indícios desse movimento metacognitivo, como os seguintes recursos metadiscursivos: retomadas e repetições (mesmo ponto de vista), além de exemplificações ("já que convivemos com ela no nosso dia a dia sem nenhum problema").

Ainda, a marca discursiva "sem dúvida" também nos ajuda a perceber que tipo de movimento está em curso. A interrupção provisória entre os dois registros seguida de uma retomada que imprime, a partir dessa marca, um grau de confiabilidade/validade maior ao que já foi dito anteriormente sugere não somente uma tentativa do enunciador de confirmar o que disse e um controle enunciativo subjacente ao seu discurso, mas denota ainda a presença de movimentos típicos de uma interrupção simples, os quais, por sua vez, se caracterizam como um movimento do tipo mantenedor. 


\title{
Monitoramento elaborador - Aluno Edson
}

\author{
Recorte: análise do Registro 3
}

Quadro 4 - Reprodução do Registro 3, correspondente à resposta de Edson para a questão "Radioatividade: vida ou morte? Qual sua opinião sobre o tema neste momento e como chegou a ela?"

\begin{abstract}
"Radioatividade é vida, em sua maioria. Pode ser usada para o bem ou para o mal, mas o bem prevalecerá se houver bom senso entre os seres humanos. Tenho uma opinião muito parecida com a de antes do estudo e do debate, só que mais fundamentada. A questão da mídia trazer incessantemente os aspectos ruins da radioatividade já me denunciava que havia interesse naquele bombardeio de informações e que não existiam apenas pontos negativos quando se trata de radioatividade.

0 debate veio a confirmar minha tese e hoje sei que as aplicações da radioatividade para nosso cotidiano são muitas e nem nos damos conta, a maioria da população deve conhecer uma ou duas aplicações para o bem, como os Raios X, por exemplo, e com certeza sabe do que aconteceu em Fukushima e Hiroshima, tomando isso como uma coisa que deve terminar com todas as pesquisas relativas ao assunto".

\begin{tabular}{|c|c|}
\hline Como? & "Já tinha uma opinião com base na observação das notícias veiculadas na mídia sobre o tema e minha pouca vivência escolar \\
sobre 0 assunto." & {$[.]$.}
\end{tabular}
\end{abstract}

Fonte: protocolo da pesquisa.

Movimentos autorreflexivos que caracterizamumacompanhamentosobreaprópria atividade discursiva e um desenvolvimento do próprio pensamento - relacionados a um tema em questão - podem ser observados em um mesmo discurso de um único interlocutor presente, como podemos notar nesse recorte de Edson. Isso porque, com base na concepção de linguagem e de argumentação adotadas neste estudo, não é necessária a presença de mais de uma pessoa para que um debate aconteça. Debates entre diferentes lados de uma mesma situação, diferentes posturas, concepções, opiniões, são constantemente travados por nós, sempre que precisamos tomar uma decisão ou compreender algo mais precisamente. Isto dá o caráter dialógico à argumentação.

Edson, nesse registro, confirma um posicionamento já assumido desde o Registro 1, embora naquele momento ainda pouco fundamentado. Assim, mais do que mostrar que ele permanece com a mesma posição, nesse Registro 3 fica clara a tentativa de Edson de fundamentar seu posicionamento. Na verdade, ele mesmo explicita isso quando diz "Tenho uma opinião muito parecida com a de antes do estudo e do debate, só que mais fundamentada". Apesar de ele nos presentear com essa fala, é também nas marcas discursivas mais sutis que apoiamos nossa análise e defendemos que, nesse recorte, podemos encontrar um metapensamento do tipo elaborador em curso.

Esse pode ser observado nas modalizações que aparecem em seu discurso, por meio das expressões "em sua maioria”, "incessantemente" (quantificador de intensidade, CHABROL, 1994), "deve conhecer" (dever + verbo no infinitivo como indicador modal, KOCH, 2000) e "com certeza" (indicador modal, KOCH, 2000). Essas marcas já indicam, portanto, a presença de um funcionamento metacognitivo, uma vez que mostram que o enunciador pensa não só no que dizer, mas em como dizer. Contudo, apontamos antes que, além das modalizações, o que caracteriza discursivamente um movimento metacognitivo do tipo elaborador é a presença de interrupções com adições, mas sem ruptura de construção. Essas se caracterizam por dois caminhos possíveis: (1) a inclusão/inserção de uma ou mais proposições dentro daquela que está sendo construída, sem ruptura da mesma, geralmente adicionando-se justificativas; e (2) antecipação de contra-argumentos, o que permite que o enunciador se defenda do avanço de objeções e críticas que podem ser direcionadas a ele. Nesse último caso, tudo se passa como se 
dois enunciadores diferentes colaborassem: o primeiro produzindo um discurso, e o segundo julgando os riscos presentes nesse discurso e intervindo a partir de um metadiscurso de defesa para proteger o primeiro.

Além da ocorrência do primeiro caminho - observado no discurso de Edson em vários momentos quando, por exemplo, aponta sua maior fundamentação (já citada acima), quando diz "hoje sei que as aplicações da radioatividade para nosso cotidiano são muitas” e quando insere a justificativa "Raios X, por exemplo" -, chamamos atenção para a ocorrência do segundo caminho, justamente pelo fato de o mesmo não acontecer de forma tão explícita.

Pode ser observado, justamente depois de Edson afırmar que sua opinião está mais fundamentada, que ele interrompe seu fio discursivo em defesa da vida ou da prevalência do bem, conforme diz no primeiro parágrafo, para retificar a opinião subjacente ao seu discurso. Entretanto, é importante notar que Edson não faz essa interrupção no sentido de mudar de direção, mas sim de corrigi-la por uma formulação mais adequada que inclua já a resposta a possíveis objeções vindas de um posicionamento contrário. Assim, antes que um interlocutor o interpele defendendo o lado "morte" da radioatividade, a partir do discurso produzido na mídia, Edson já inclui essa possível contra-argumentação no seu texto, adicionando um discurso em defesa da "vida”. Esse movimento é chamado por Chabrol (1994) de regulação egocêntrica antecipada e é definido como um mecanismo regulatório sócio-cognitivo-linguístico que permite ao sujeito enunciador antecipar a evolução do sujeito interpretador entrando na posição deste e tentando inferir como ele reagirá à sua proposta, com certa plausibilidade. 0 movimento realizado discursivamente por Edson, a partir de interrupções com adição e sem ruptura, nos ajuda a perceber um movimento metacognitivo elaborador em curso.

$\mathrm{Na}$ construção organizada por Edson no segundo parágrafo, pode-se observar a concepção intuitiva que ele tinha antes de estudar o assunto e que foi confirmada pelo debate ("o debate veio a confirmar minha tese"). Ou seja, o debate lhe deu subsídios para ele argumentar o quanto no discurso da mídia prevalecem os possíveis aspectos maléficos da radioatividade, sendo concedido pouco espaço aos benefícios - que, para ele, são muitos e dos quais acabamos não nos dando conta ("a maioria da população deve conhecer uma ou duas aplicações para o bem, como o Raio X, por exemplo, e com certeza sabe do que aconteceu em Fukushima e Hiroshima”). Vemos, ainda, na sua resposta ao "como", que o debate confirmou sua tese, o que nos indica a relação dos movimentos de reflexividade do pensamento com a situação de argumentação oportunizada pela atividade.

\section{Monitoramento reconstrutor - Aluna Ana}

\section{Recorte: análise do Registro 1 para 02}

Quadro 5 - Reprodução do Registro 1, correspondente à primeira resposta de Ana para a questão "Radioatividade: vida ou morte?"

"É comum ouvirmos falar sobre a radioatividade e os riscos e benefícios que ela traz à sociedade. Entretanto, poucas pessoas têm conhecimento considerável ou profundo sobre esse tema. Eu, por exemplo, (nunnea vi nem comieut) só ouço falar, mas sei pouco a respeito. Sei que é utilizado para o bem e para o mal, às vezes sem más intenções. Para responder à essa "pergunta-título", precisamos pôr em pauta os benefícios e os malefícios trazidos pela Radioatividade. Entre os benefícios podemos destacar os avanços no campo das telecomunicações, a "invenção" do Raio-X (que hoje é essencial), a quantidade enorme de energia que existe proveniente da radioatividade, etc. São avanços consideráveis, que nos fazem pensar na Radioatividade apenas como algo positivo. Porém, é necessário pensar na outra (tado) face da situação: se por um lado a utilização de tal tipo de energia é tão proveitosa, por outro, a exposição excessiva às ondas de rádio pode trazer problemas de saúde, por exemplo. Outro malefício que pode ser apontado é o uso de tal energia para destruição (Hiroshima, Nagasaki). Acho que radioatividade é mais morte do que vida, pois os perigos causados por ela não podem ser evitados facilmente, de forma que o prejuízo é maior do que o benefício".

Fonte: protocolo da pesquisa

* Esse risco, assim como os encontrados nos demais protocolos da pesquisa, foram feitos por Ana. Foi solicitado aos alunos que, quando quisessem modificar algo no texto, não apagassem o conteúdo, mas que o riscassem para que fosse possível ao pesquisador acompanhar o percurso das ideias dos mesmos. Quaisquer outros grifos nos protocolos - como sublinhado, aspas ou parênteses - também foram feitos pela aluna. 
Quadro 6 - Reprodução do Registro 2, correspondente à resposta de Ana para a questão "Radioatividade: vida ou morte? Qual sua opinião sobre o tema neste momento e como chegou a ela?"

"Minha opinião sobre esse tema tá meio confusa agora. Ouvi muitas coisas diferentes, muitas observações válidas. 0 problema da radioatividade é muito grave e, ao mesmo tempo, necessário. Por isso, precisamos encontrar meios de conter os danos gerados por tal fenômeno antes de fazer uso tão intenso dele (como é feito hoje), afinal, não sabemos exatamente os resultados das aplicações que a radioatividade tem em nossas vidas: isso é algo que só saberemos no futuro, como sempre. Além disso, é preciso analisar a radioatividade como algo perigoso não só por seu aspecto físico-químico, mas também político (inverti o argumento agora), pois os problemas causados pela radioatividade no campo físico-químico interferem bastante no âmbito político e social, pois a possibilidade de haver (supostamente) uma guerra nuclear causa, paradoxalmente, outras guerras. Enfim, minha opinião é que a radioatividade pode significar mais vida do que morte, porém, apenas se for utilizada e estudada com bom senso".

Como?

"Eu sempre simulo uma discussão mentalmente: penso em tudo que já ouvi a respeito do assunto, imagino réplicas e, A como aconteceu nesse texto, às vezes inverto um argumento, olhando-o sobre outro ponto de vista. Agora, por exemplo, ouvi várias opiniões e as confrontei entre si e também com a minha opinião anterior, buscando uma melhor elaborada".

Fonte: protocolo da pesquisa.

Inicialmente, no Registro 1, podemos perceber que, na própria construção do posicionamento inicial, existe um diálogo argumentativo acontecendo. Não são duas pessoas dialogando, mas sim duas posições dialogando. Isso porque Ana opta por iniciar a construção de seu argumento pela separação dos dois posicionamentos possíveis a partir da pergunta-título, como ela mesma define: "precisamos por em pauta os benefícios e os malefícios”. Iniciando pelos benefícios, ela elenca três deles e, depois, utilizando um operador que contrapõe argumentos orientados para conclusões contrárias, o "porém" (KOCH, 2000), ela elenca dois malefícios do uso da radioatividade.

Ao final, no último parágrafo do primeiro registro, Ana estabiliza sua construção, marcando a formação de um argumento, ao iniciá-lo a partir do marcador argumentativo de tomada de posição "acho que”. Posicionarse depois de elencar os benefícios e malefícios denota que, nos parágrafos anteriores, a aluna não apenas os cita de forma descomprometida, mas o faz de forma avaliativa. 0 que ela chamou inicialmente de "por em pauta" se constituiu em um movimento de reflexão sobre o tema, propiciando um posicionamento inicial. 0 uso, no último parágrafo, do "mais... do que" e do "maior do que" - operadores argumentativos que estabelecem relações de comparação com vistas a uma dada conclusão (KOCH, 2000) - pode ajudar a justificar essa tomada de posição. A presença do operador argumentativo "pois" nos mostra que existe aí, nesse momento de estabilidade final, não simplesmente um ponto de vista, mas já um argumento, uma vez que o enunciado se apresenta composto de ponto de vista ("radioatividade é mais morte do que vida”, "o prejuízo é maior que o benefício") e de justificativa ("pois os perigos causados por ela não podem ser evitados facilmente").

Nesse movimento reflexivo, o lado negativo (ou, como ela diz em sua construção, "a outra face da situação") parece ter transpassado o lado positivo, não apenas rompendo com a construção do discurso de benefícios, mas tornando-o insustentável. Ao confrontar os dois lados, o positivo pareceu não poder ser equilibrado com o negativo, já que esse último se apresenta mais forte que o primeiro, desestabilizando-o. Uma das possibilidades de compreensão para o fato de esse lado negativo ter pesado mais ao final pode se referir à presença dos casos reais de Hiroshima e Nagasaki. 0 fato de esses dados de evidencialidade terem sido incorporados pode ter tornado esse lado da questão mais válido.

No entanto, esse momento de estabilidade parece não se manter no segundo registro de Ana, já que ela inicia o mesmo deixando claro seu momento de dúvida em relação ao seu posicionamento: se diz confusa e também pontua que seu estado é proveniente do debate 
realizado antes de sua escrita. Tanto no texto como no relato posterior sobre como chegou à sua opinião naquele momento, Ana declara a presença das outras vozes sendo levadas em consideração na construção da sua posição quando diz: "ouvi muitas coisas diferentes, muitas observações válidas" (no texto em que responde à pergunta proposta) ou "ouvi várias opiniões e as confrontei entre si e também com a minha opinião anterior" (na resposta ao como ela chegou à opinião descrita). É muito relevante comentar a clareza com que ela nos permite perceber o movimento reflexivo que realiza mentalmente, simulando, como ela mesmo diz, estar, a cada momento, em um lado, em uma posição diferente, e assumindo diferentes papéis/posicionamentos de forma a permitir que o diálogo interno aconteça (“[...] às vezes inverto um argumento, olhando-o sobre outro ponto de vista"). Assim, Ana constrói mentalmente o ambiente necessário à emergência de uma situação de argumentação dialógica. Além disso, do ponto de vista da análise do seu funcionamento metacognitivo, percebemos o forte valor modal desses seus enunciados, sobretudo quando Ana aponta para sua própria atividade de fala ("inverti o argumento agora”). Nessa forma de construção, o falante pensa não só o que dizer, mas como dizer, isto é, o enunciador comenta sua própria atividade discursiva, o que constitui uma atividade essencialmente reflexiva.

É válido lembrar que, antes do debate, Ana havia estabilizado sua posição ("Acho que radioatividade é mais morte do que vida, pois os perigos causados por ela não podem ser evitados facilmente, de forma que o prejuízo é maior do que o benefício"). Assim, é interessante perceber que a sua presença nas discussões em sala de aula fez Ana desestabilizar seu posicionamento. Um detalhe bastante importante de seu segundo texto se refere ao fato de ela ter dito que ouviu muitas observações diferentes e válidas que a deixaram confusa. No entanto, quando se espera que ela traga posições contrárias à sua posição anterior que justifiquem a confusão que agora a invade, ela traz mais justificativas voltadas à sua primeira posição, isto é, voltadas para os malefícios da radioatividade: "o problema da radioatividade é muito grave e, ao mesmo tempo, necessário"; "não sabemos exatamente os resultados das aplicações que a radioatividade tem em nossas vidas"; "os problemas causados pela radioatividade no campo físico-químico interferem bastante no âmbito político e social, pois a possibilidade de haver (supostamente) uma guerra nuclear causa, paradoxalmente, outras guerras".

A aluna constrói ainda um argumento a partir de um ponto de vista que se inicia por um indicador modal ("precisamos"), o que sinaliza a importância daquilo que será dito $(\mathrm{KOCH}$, 2000): "precisamos encontrar meios de conter os danos causados por tal fenômeno antes de fazer uso tão intenso dele". Após esse ponto de vista, Ana traz o operador argumentativo "afinal" - que, segundo Koch (2000), funciona como introdutor de uma justificativa relativa a um enunciado anterior - para apresentar sua fundamentação: "afınal, não sabemos exatamente os resultados das aplicações que a radioatividade tem em nossas vidas". Como apontamos acima, toda essa construção não a ajuda a justificar sua confusão atual, uma vez que claramente a mesma está, até aqui, a serviço de seu argumento inicial.

Acompanhando a construção do seu discurso, no entanto, encontramos uma conclusão paradoxal. Isso porque, quando o leitor imagina que ela concluirá mantendo sua posição - agora com um suporte maior dado pelos argumentos incorporados -, Ana interrompe o fluxo de suas reflexões como se as mesmas tivessem sido transpassadas em sua rota por uma nova possibilidade de construção (CHABROL, 1994). Dessa forma, ela enuncia: "Enfım, minha opinião é que a radioatividade pode significar mais vida do que morte". Aqui percebemos um movimento do tipo reconstrutor, já que há uma interrupção com ruptura de construção e de autocorreção (CHABROL, 1994), que fez parecer o antecedente inadequado ou insatisfatório, exigindo, no 
enunciado consequente, uma mudança. Poder-seia pensar que toda construção desse registro seria sem sentido, caso o enunciado de Ana parasse por aí; no entanto, quando continuamos a leitura, encontramos um operador argumentativo, o “porém”, que vem para contrapor o argumento que está sendo orientado para a conclusão contrária, no intuito de flexibilizá-lo $(\mathrm{KOCH}$, 2000). Isto é, quando Ana complementa seu enunciado com "porém, apenas se for utilizada e estudada com bom senso", ela dá sentido para toda sua construção de apoio ao lado maléfico da radioatividade.

Assim, embora em seu discurso não esteja explícito o que desestabilizou sua posição inicial, nos interessa observar que, no decorrer da situação de argumentação real e/ou de suas simulações mentais de discussões a respeito do tema, a posição contrária (radioatividade como vida) passou a ser considerada a ponto de retificar o curso do seu posicionamento. Observamos nesse ponto uma regulação retroativa de sua construção discursiva, ou, como chama Chabrol (1994), uma regulação egocêntrica retroativa, proveniente da reflexão interna e da demanda de reconstrução.

\section{Considerações finais}

A possibilidade de participar da formação de alunos que, para além de depositários de um conhecimento formal e etéreo, constituam-se indivíduos em eterna construção a partir de uma postura aberta, crítica, reflexiva, comprometida e ética em relação ao conhecimento tem sido o desejo de muitos educadores da atualidade. Alunos que compreendam a intrínseca relação entre a constituição do conhecimento e da sociedade, bem como sua própria constituição enquanto indivíduos. Entendemos que, mais do que desejar fazer parte, os educadores também se encontram implicados na construção de uma educação dessa natureza.

0 movimento CTS, propondo um ensino que promova a interação do aluno com o conhecimento científico articulado às suas dimensões sociais, tem trazido interessantes contribuições no que se refere à importância de os educadores pensarem em práticas pedagógicas que oportunizem o desenvolvimento da reflexão e da criticidade. Trabalhar um tema como Radioatividade de forma descontextualizada, focando-se na memorização de conceitos, seria considerar o conhecimento a partir de uma neutralidade científica absoluta, e o homem de forma completamente dissociada de seu ambiente, de seu contexto social e histórico.

Foi partindo de questões como essas que este estudo se propôs a analisar a argumentação em sala de aula como possível prática pedagógica que seja capaz de possibilitar a construção de conhecimentos de forma contextualizada e o desenvolvimento metacognitivo dos alunos.

Em confluência com trabalhos anteriores (DE CHIARO, 2006; LEITÃO, 2007, 2008; DE CHIARO; AQUINO, 2013), o presente estudo corrobora a tese de que esse tipo específico de discurso, a argumentação, por sua organização discursiva peculiar, pode, de fato, se constituir em uma interessante alternativa para fazer emergir formas de pensamento sofisticadas, como as que definem um pensamento crítico e reflexivo. Ao serem interpelados a tomarem uma posição frente à questão sociocientífica levantada, os alunos pesquisados mostraram um funcionamento autorreflexivo que caracteriza um nível metacognitivo de pensamento. Além de a análise dos dados ter demonstrado a presença de movimentos autorreflexivos nos alunos, permitiu-nos também observá-los acontecendo em suas três formas: mantenedora, elaboradora e reconstrutora. Defende-se, pois, que, se um funcionamento metacognitivo oportunizado pela utilização da argumentação na sala de aula se constituiu em um caminho fértil para a construção de conhecimentos e de indivíduos críticos, reflexivos e implicados com a construção do real, então atividades de caráter argumentativo, enquanto prática pedagógica, podem e devem fazer parte do planejamento de aulas dos professores. Entendemos, por fim, que uma conclusão como essa deve ser levada em consideração quando se pensa sobre formação de professores. 


\section{Referências}

AULER, Décio; DELIZOICOV, Demétrio. Ciência-tecnologia-sociedade: relações estabelecidas por professores de ciências. Revista Electrónica de Ensenãnza de las Ciencias, Barcelona, v. 5, n. 2, p. 337-355, 2006.

BAKER, Michael. Argumentative interactions and the social construction of knowledge. In: MIRZA, Nathalie Muller; PERRET-CLERMONT, Anne-Nelly (Ed.). Argumentation and Education: theoretical foundations and practices. Dordrecht: Springer, 2009. p.127-144.

CANDELA, Antonia. A construção discursiva de contextos argumentativos no ensino de ciências. In: COLL, César; EDWARDS, Derek (Ed.). Ensino, aprendizagem e discurso em sala de aula: aproximações ao estudo do discurso educacional. Porto Alegre: Artes Médicas, 1998. p. 143-169.

CARON, Jean. Les régulations du discours: psycholinguistique et pragmatique du language. Paris: Presses Universitaires de France, 1983.

CHABROL, Claude. Discours du travail social et pragmatique. Paris: Presses Universitaires de France, 1994.

CHABROL, Claude; OLRY-LOUIS, Isabelle. Interactions communicatives et psychologie. Paris: Sorbonne Nouvelle, 2007.

CHABROL, Claude; RADU. Miruna. Psychologie de la communication et de la persuasion: théories et applications. Bruxelas: De Boeck Université, 2008.

DE CHIARO, Sylvia. A construção do conhecimento em uma sala de aula de história: o papel da argumentação, 2001. Dissertação (Mestrado em Psicologia Cognitiva) - Universidade Federal de Pernambuco, Recife, 2001.

DE CHIARO, Sylvia. Argumentação em sala de aula: um caminho para o desenvolvimento da autorregulação do pensamento, 2006. Tese (Doutorado em Psicologia Cognitiva) - Universidade Federal de Pernambuco, Recife, 2006.

DE CHIARO, Sylvia; AQUINO, Kátia Aparecida da Silva. Argumentação e autorregulação do pensamento em aulas de química. Recife: UFPE, 2013. Trabalho apresentado no III Seminário Internacional de Argumentação na Escola. Desenvolvimento de Competências e Promoção de Intervenç̧̃̃es, do Núcleo de Pesquisa da Argumentação, Universidade Federal de Pernambuco.

DE CHIARO, Sylvia; LEITÃO, Selma. 0 papel do professor na construção discursiva da argumentação em sala de aula. Psicologia, Porto Alegre, v. 18, n. 3, p. 350-357, 2005.

FATARELI, Elton Fabrino; FERREIRA, Luciana Nobre de Abreu; QUEIROZ, Salete Linhares. Argumentação no ensino de química: textos de divulgação científica desencadeando debates. Acta Scientiae, Canoas, v. 16, n. 3, p. 613-630, 2014.

FATARELI, Elton Fabrino et al. Mapeamento de textos de divulgação científica para planejamento de debates no ensino de química. Química Nova na Escola, São Paulo, v. 37, n. 1, p. 11-18, 2015.

FLAVELL, John Hurley. Metacognition and cognitive monitoring: a new area of cognitive developmental inquiry. American Psychologist, v. 34, n. 10, p. 906-911, 1979.

JIMENEZ-ALEIXANDRE, María Pilar. A argumentação sobre questões sócio-científicas: processos de construção e justificação do conhecimento em sala de aula. Educação em Revista, Belo Horizonte, n. 43, p. 13-33, 2006.

JIMENEZ-ALEIXANDRE, María Pilar; ERDURAN, Siebel. Argumentation in science education: an overview. In: JIMENEZ-ALEIXANDRE, María Pilar; ERDURAN, Siebel (Ed.). Argumentation in science education: perspectives from classroom-based research. Dordrech: Springer, 2008. p. 47-70.

JIMENEZ-ALEIXANDRE, María Pilar; BROCOS, Pablo. Desafios metodológicos na pesquisa da argumentação em ensino de ciências. Revista Ensaio, Belo Horizonte, v. 17, n. especial, p. 139-159, 2015.

KOCH, Ingedore Villaça. A inter-ação pela linguagem. São Paulo: Contexto, 2000.

KOCH, Ingedore Villaça; MORATO, Edwiges Maria; BENTES, Anna Christina. Referenciação e discurso. São Paulo: Contexto, 2005.

KUHN, Deanna. Education for thinking. Cambridge: Harvard University Press, 2005.

KUHN, Deanna. The skills of argument. Cambridge: Cambridge University Press, 1991.

LEITÃO, Selma. Arguing and Learning. In: LIGHTFOOT, Cynthia; LYRA, Maria (Ed.). Challenges and strategies for studying human development in cultural contexts. Roma: Firera \& Liuzzo Group, 2009. p. 221-251.

LEITÃo, Selma. Argumentação e desenvolvimento do pensamento reflexivo. Psicologia, Porto Alegre, v. 20, n. 3, p. 454-462, 2007. 
LEITÃO, Selma. La dimensión epistémica de la argumentación. In: KRONMÜLLER, Edmundo; CORNEJO, Carlos (Ed.). La pregunta por la mente: aproximaciones desde Latinoamérica. Santiago de Chile: JCSáez, 2008. p. 89-119.

LEITÃO, Selma. O lugar da argumentação na construção do conhecimento em sala de aula. In: LEITÃO, Selma; DAMIANOVIC, Maria Cristina (Ed.). Argumentação na escola: 0 conhecimento em construção. Campinas: Pontes. 2011. p. 13-46.

MENDES, Mírian Rejane Magalhães; SANTOS, Wildson Luiz Pereira dos. Argumentação em discussões sociocientíficas. Investigações em Ensino de Ciências, Porto Alegre, v. 18, n. 3, p. 621-643, 2013.

MENDONÇA, Paula Cristina; JUSTI, Rosária da Silva. Ensino-aprendizagem de ciências e argumentação: discussões e questões atuais. Revista Brasileira de Pesquisa em Educação em Ciências, Belo Horizonte, v. 13, n. 1, p. 1877-216, 2013.

MERCER, Neil. Classroom talk and the development of self-regulation and metacognition. British Journal of Educational Psychology, n. 10, p. 1-23, 2013. Monograph series II: Psychological aspects of education. Self-regulation and dialogue in primary classrooms.

MUNDIM, Juliana Viégas; SANTOS, Widson Luiz Pereira dos. Ensino de ciências no ensino fundamental por meio de temas sociocientificos: análise de uma prática pedagógica com vista à superação do ensino disciplinar. Ciência \& Educação, Bauru, v. 18, n. 4, p. 787-802, 2012.

NASCIMENTO, Silvania Sousa; VIEIRA, Rodrigo Drumond. Contribuições e limites do padrão de argumento de Toulmin aplicado em situações argumentativas de sala de aula de ciências. Revista Brasileira de Pesquisa em Educação em Ciências, Belo Horizonte, v. 8, n. 2, p. 1-20, 2008.

PINHEIRO, Nilcéia Aparecida Maciel; SILVEIRA, Rosemari Monteiro Castilho Foggiatto; BAZZO, Walter Antonio. Ciência, tecnologia e sociedade: a relevância do enfoque CTS para o contexto do ensino médio. Ciência \& Educação, Bauru, v. 13, n. 1, p. 71-84, 2007.

RAPANTA, Chrysi; GARCIA-MILA, Merce; GILABERT, Sandra. What is meant by argumentative competence? An integrative review of methods of analysis and assessment in education. Review of Educational Research, v. 83, n. 4, p. 483-520, 2013.

SASSERON, Lúcia Helena; CARVALHO, Anna Maria Pessoa. Ações e indicadores da construção do argumento em aula de ciências. Ensaio, Belo Horizonte, v. 15, n. 2, p. 169-189, 2013.

SCHWARZ, Baruch. Argumentation and learning. In: MIRZA, Nathalie Muller; PERRET-CLERMONT, Anne-Nelly (Ed.). Argumentation and education: theoretical foundations and practices. Dordrecht: Springer, 2009. p. 91-126.

VYGOTSKY, Lev Semenovitch. Pensamento e linguagem. São Paulo: Martins Fontes, 1993.

WHITEBREAD, David. Self-regulation in young children: its characteristics and the role of communication and language in its early development. British Journal of Educational Psychology, n. 10, p. 25-43, 2013. Monograph series II: Psychological aspects of education. Self-regulation and dialogue in primary classrooms.

Recebido em: 21.12.2015

Aprovado em: 21.06.2016

Sylvia De Chiaro é professora do Departamento de Psicologia e Orientação Educacionais no Centro de Educação e do Programa de Pós-Graduação em Educação em Ciências e Matemática, do Centro Acadêmico do Agreste, ambos da Universidade Federal de Pernambuco (UFPE). Pesquisadora do Núcleo de Pesquisa da Argumentação - UFPE (NupArg).

Kátia Aparecida da Silva Aquino possui pós-doutorado em educação tecnológica e é docente do Colégio de Aplicação da Universidade Federal de Pernambuco. Atua em pesquisas sobre práticas de inovação e experimentação didático-pedagógicas e formação docente à luz da teoria da aprendizagem significativa. 